\title{
The Influence of Bible on Western Culture
}

\section{Peng Xiamei}

English Department, School of Foreign Languages, North China Electric Power University, Beijing, China

\section{Email address:}

pengxiamei@139.com

\section{To cite this article:}

Peng Xiamei. The Influence of Bible on Western Culture. Science Innovation. Vol. 4, No. 2, 2016, pp. 61-64. doi: 10.11648/j.si.20160402.17

Received: March 26, 2016; Accepted: April 8, 2016; Published: April 14, 2016

Abstract: The Bible, the Holy Book of Christianity, has played an inevitably magnificent role in Western culture; therefore, it is no exaggeration to say that without a thorough reading of the Bible, it would be impossible for anyone to have a better understanding of the Western culture. In light of this, the author intends to highlight the influence the Bible has on the Western culture from the perspectives of political system, literature, language, art and daily life, thus hoping to provide a different angle to the deeper interpretation of the Bible and its influence on the Western Culture.

Keywords: The Holy Bible, the Western Culture, Influence

\section{《圣经》对西方文化的影响}

\section{彭霞媚}

外国语学院英语系, 华北电力大学, 北京, 中国

\section{邮箱}

pengxiamei@139. com

摘要: 基督教的圣书一一 《圣经》, 两千多年来对西方的文化有着举足轻重的作用, 可以说, 不了解《圣经》就无法 深入理解西方的文化及其内涵。因此，本文拟从西方的政治体系、文学、语言、艺术及其日常生活五个方面分别来阐 述《圣经》对西方文化的影响，以期提供一个阐释《圣经》的不同角度及其对西方文化的影响。

关键词: 圣经, 西方文化, 影响

\section{1. 引言}

研究文化不能不研究宗教, 研究西方文化, 更不能不 研究代表了它的精神实质的核心一一基督教。基督教从创 立至今已有两千多年的历史，在这漫长的历史进程中，基 督教从其发源地巴勒斯坦扩展到全世界各地，成为世界上 信徒最多, 影响最大的宗教。由于基督教在西方主流文化 中的显著地位, 人们常误认为基督教是西方人的宗教。其 实, 基督教源于东方——即现在的巴勒斯坦地区。最初基 督教随着其信徒传入欧洲的时候, 曾遭遇以古罗马为首的 希腊文化的强烈抵制, 最终两种文化一一东方的希伯来文 化和西方的希腊文化, 逐渐融合, 产生了新的文化一一基
督教文化。刘建军 [1]指出, “所谓的基督教文化, 就是 以基督教思想原则来考虑人和世界关系的思维过程本身”。 “两希” 文化 (希伯来文化和希腊文化) 进而成为西方文 化的主流文化, 并渗透在西方文化的各个领域, 产生日益 重要的影响。可以说, 不了解基督教及其文化也就不能真 正理解西方文化的精髓。

基督教的源头为希伯来《圣经》, 亦称为《圣经旧约》, 是世界文化、文学史上的奇菂。从中世纪以来, 它逐渐成 为西方文化的支柱, 其影响渗透到文化的各个领域: 文学、 艺术、政治体系、语言、日常生活等。从某种程度上说, 西方文化, 尤其近现代文化的发展和《圣经》息息相关。 无数的文学家、思想家、哲学家深受其影响, 称之为绝妙 的经典之作, 无可超越。 
国内很多学者从各个方面对圣经做了大量的研究: 朱 维之是将《圣经》作为文学作品进行研究的先驱, 后继者 也在此方面作出大量贡献, 如邱永旭、陆扬、徐亮等; 刘 意青引进了圣经叙事的理论和概念; 叶舒宪对圣经中出现 的比喻和意象进行了分析; 梁工从西方文艺理论与《圣经》 关系角度进行了阐述; 王新生对圣经的内容进行了文本的 细读, 从更深层次对圣经进行挖掘理解; 兴荣健对圣经中 的人物从全新的角度进行了点评……本文在纵览前人研 究成果的基础上, 从文化、文学等角度来探究圣经对西方 文明的影响, 以期对圣经有更全面的了解。

\section{2. 《圣经》对西方文化的影响}

基督教文化是西方文化的一个重要组成部分, 根据赵 复三 [2]在《基督教与西方文化》中的观点, 《圣经》及 基督教文化与西方文化的关系主要体现在以下几点上: 第 一, 政治上, 基督教文化加强了欧洲统一的意识。欧洲统 一是二十世纪的共同意识, 但是欧洲内在的一致性的形成 是在于欧洲各国文化都是受基督教文化的影响。由于新大 陆移民与文化交流, 在北美洲、南美洲及太平洋文化中也 能看到基督教文化的影响。第二, 基督教文化与西方文学 艺术有一定的关系。中世纪的哲学探讨如宇宙渊源、宇宙 本体、人生价值、善恶伦理等等观念都受到了基督教的影 响。西方的艺术如绘画、建筑、雕刻、音乐都与基督教会 的思想与活动分不开。第三, 《圣经》对西方语言的影响 渊源流传。第四, 基督教对西方人日常生活的影响极其深 远。总之, 可以说, 一个人从摇篮到坟墓, 从思想到言行 到日常生活, 都不同程度上受到了《圣经》的影响。正如 斯蒂芬 - 米勒 [3]指出的， “正是《圣经》的信息广为传 播, 对法律、文学和戏剧造成了深远的影响”。下文将从 上述提到的几个方面分别论述《圣经》对西方文化的影响。

\section{1. 《圣经》对西方政治体系的影响}

中世纪西欧的政治体系及其主流意识形态主要受到 基督教及其经卷 《圣经》的影响, 主要表现在: 首先, 基 督教是灵魂上天堂的唯一途径; 其次, 基督教教堂成为欧 洲最大的经济实体; 再次, 教堂把世俗王权玩弄于股掌之 中。“罗马天主教会控制了社会的政治、经济、文化资源, 掌握了巨大的权力。最后, 其律法如 “摩西十诫” 正是 欧洲中世纪法律、伦理、道德规范的基础。更为重要的是,

《圣经》对催生近现代西方民主政治体制也有着不可估量 的作用。《圣经》中关于基督教的宗教典籍、神学统治及 政治实践等孕育了近代现西方宪法和宪制文化的基本要 素, 对近现代西方宪政的基本理念、制度和实践都产生了 十分深刻的影响。可以说, 西方宪法植根于西方基督教的 信仰体系及其表述世俗秩序意义的政治思想之中。十八世 纪初缘起于欧洲的启蒙运动提倡民主、平等、自由等思想, 同时倡导政治体制改革，提出 “三权分立” 的原则，其实 也都是来源于 《圣经》中上帝创世以及基督救世的博爱、 平等思想。

现今，英美等西方国家的主流文化是基督教文化。美 国是一个宗教国家, 百分之九十以上的人信仰上帝, 有百
分之四十的人每周去教堂。当今美国总统奥巴马就是一个 很虔诚的基督徒。在美国的总统就职仪式上，历届新任总 统都要手按《圣经》, 向《圣经》宣誓。从这一点可以看 出, 宗教与美国宪政的联系是密不可分的。众所周知, 美 国的《独立宣言》为美国最重要的立国文书之一。此宣言 强调人人生而平等, 是造物主上帝赋予每个人的不可剥夺 的权利。如今, 甚至在美元纸钞上, 我们也可以看到印在 上面的 “上帝吾人信仰 (In God We Trust)” 的字样, 表明了西方政府及民众对基督教宗教情怀的认可。由此可 见, 基督教对西方国家政治的形成和发展有很大的影响。

\section{2. 《圣经》对西方文学的影响}

西方文学中每一位重要的作家几乎都接受过《圣经》 文学的熏陶, 都曾受过《圣经》语言的训练。作为语言学 的一个重要来源, 《圣经》的语言在文学作品中的影响是 非常明显、非常深刻的, 它不仅为文学创作提供了大量取 之不尽、用之不竭的题材, 而且还给语言特别是英语语言 注入了充足的血液。因为《圣经》蕴含着极高的文化和文 学价值, 一代又一代的西方作家从中引经据典选取素材、 改写情节、引用人物、汲取灵感。假如没有《圣经》和基 督教, 西方文学史可能要重新撰写。在后代名家们的流芳 百世、经久不衰的经典中, 我们经常得以见到《圣经》熟 悉的 “身影”。《圣经》在西方乃至世界文化发展史上的 价值与地位已远远的超出其宗教的范畴, 它之所以成为历 代学者们取之不尽、用之不竭的语言和艺术宝库, 这与其 语言里所蕴涵的深层文化内涵是分不开的。

《圣经》对英美文学的影响主要表现在以下方面：(1) 直接援引《圣经》中的词句或人名为作品标题或人物名称。 例如: 海明威的《太阳照样升起》（The Sun Also Rises） 来源于《旧约 传道书》; 威廉・福克纳的《押沙龙, 押 沙龙》 (Absalom, Absalom!) 来源于《撒母耳记下》; 斯坦贝克的《伊甸园以东》 (The East Of Eden) 来源于 《创世纪》。(2) 直接从 《圣经》里汲取题材, 并在此 基础上进行再创作。例如: 弥尔顿 (John Milton) 的诗 歌里弥漫着基督信仰的内容, “在经历了 20 年的政治奔波 后, 他最终意识到并回归他一生的真正使命: 以他天天诵 读的《圣经》为故事题材, 写出 《圣经》题材的文学作品” [4] 一一《失乐园》(Paradise Lost), 《复乐园》(Paradise Regained），《力士参孙》（Samson Agonistes）。这三 部曲都是基于圣经中大家耳熟能详的故事进行加工、改编 的, 甚而与《圣经》遥相呼应, 为后人创造出自己独到的 《圣经》传说。；王尔德 (Oscar Wilde) 的《莎乐美》 (Salomé ) 也是取材于《福音书》中关于施洗礼者圣约 翰和希律王女儿莎乐美之间的故事。（3）以《圣经》里 的基督教思想与教义为主题进行创作。如, 班扬 (John Bunyan）的《天路历程》（The Pilgrim's Progress）; 柯勒律治 (Samuel Taylor Coleridge) 的《古舟子咏》

(The Rime of the Ancient Mariner); 莎士比亚 (William Shakespeare) 的《罗密欧与朱丽叶》(Romeo and Juliet), 《暴风雨》 (The Tempest) ; 狄更斯 (Charles Dickens) 的《双城记》 (A Tale of Two Cities); 霍桑 (Nathaniel Hawthorne) 的《红字》 (The Scarlet Letter); 梅尔 
维尔 (Herman Melville) 的《白鲸》 (Moby Dick) 等。 （4）把《圣经》故事里的寓意融汇到作品的情节或人物 的性格里, 通过比喻、隐喻或象征等手法使这些故事发 挥有力的陪祄作用。例如: 夏洛蒂 - 勃朗特 (Charlotte Bronte ) 的《简爱》 (Jane Eyre) ; 狄更斯的《大卫・科 波菲尔》（David Copperfield）; 海明威的《永别了, 武器》 (A Farewe11 to Arms) ; 斯坦贝克的《愤怒的 葡萄》（The Grapes of Wrath）；菲茨杰拉德（Francis Scott Fitzgerald) 的《了不起的盖茨比》（The Great Gatsby) 等。

此外, 《圣经》中丰富多彩的表现方法和艺术形式对 一些作家也产生了很大的影响。如莎士比亚经常模仿《圣 经》中先知文学、启示文学的手法在其戏剧中埋设伏笔, 制造悬念。夏洛蒂・勃朗特的《简爱》处理大量引用《圣 经》中的典故以外, 书中主人公简 - 爱的人生历程也是深 受神的指引才能经受住各种考验, 最终获得自己的幸福。 此外，书中涉及的一系列意象也和圣经息息相关，如水、 火的意象与《圣经》中 “水代表破坏性的力量, 火代表重 生、热情紧密相关” [5]。全书的词句、节奏和抑扬顿挫, 也都深受钦定本《圣经》的影响。福克纳从小就深受《圣 经》影响，《旧约》更是他最喜欢并反复阅读的书籍之一。 《圣经》不仅决定了他的世界观、历史观、伦理价值观的 形成, 而且深深渗透到他的思维结构、艺术表现方式之中, “《圣经》的宗教原型意象也在不自觉中呈现于作品之中, 从而形成其独特的象征手法” [6]。除此之外, 在西方作 家中, 我们可以还可以很容易地发现康拉德、陀思妥耶夫 斯基、托尔斯泰、狄更斯、雨果、海明威、爱伦 - 坡、斯 坦贝克、马克 - 吐温等深受《圣经》影响, 他们的文学作 品, 从圣经文化中吸收了丰富的营养。

总之, “《圣经》在成书后两千多年来之所以经久不 衰, 不仅仅在于它的宗教力量, 还在于它自身巨大的文学 价值以及对西方文学乃至世界文学所产生的深远影响。” [7] 只有对 《圣经》有了总体的认识和了解, 我们才能够 更好的理解西方的文学。

\section{3. 《圣经》对西方语言的影响}

《圣经》对以印欧语系为代表的西方语言有着不可磨 灭的深远影响, 主要表现在《圣经》规范了英语、德语等 欧洲各国的语言文字。《圣经》从希腊文、希伯来文及拉 丁文被译成英语经历了几个重要阶段。首先, 十四世纪的 约翰・威克利夫在 1382 年到 1384 年间把《圣经》从拉丁文 译成了英文。他的译本曾一度风行欧洲, 对当时英国的语 言文字、散文都产生了巨大的影响。之后, 威廉・廷尔德 于1526年出版了《新约》英译本, 奠定了《圣经》英译本 的基础。他的译文语言通俗易懂, 对语言的规范化和英国 文学有很深刻的影响。最重要的一次《圣经》翻译是英王 詹姆士一世授意、坎特伯雷大主教募人翻译的钦定本《圣 经》。《钦定圣经译本》出版于1611年, 它一反伊丽莎白 时代辞藻华丽的文风, 语言简洁、古朴、典雅, 具有很强 的表现力。它的出现不仅进一步确立了规范而统一的英语, 而且大大拓宽了它的使用面, 使这一语言从狭小的学术、 文艺领域走了出来, 进入广大社会的千家万户之中。钦定
本的成功奠定了现代英语的基础, 被誉为英国散文最伟大 的丰碑。现代《圣经》英文版基本指的都是英王钦定本。 在德国, 马丁・路德也通过翻译《圣经》对德语语言进行 了大张阔斧的改革, 规范了现代德语的用法。除此之外, “西欧其他各国语言文字的青理和规范化, 几乎都是从 《圣经》的翻译开始的。” [8]

“《圣经》对西方语言的影响还表现在它为西方语言 输入了新鲜的血液, 增添了大量的习语, 格言, 典故词, 派生词等 “, 从而丰富, 发展和完善了欧洲各国语言。比 如, 英语中有很多和基督教直接相关的词汇, 如:Trinity (三位一体)、TheCatholic church(天主教)、 Reformation (宗教改革)、protestants (新教徒)、 Puritans (清教徒)、Mass (弥撒)。《圣经》中的很多用语 也在英语中的有广泛的使用, 如Juda' skiss (犹大的吻, 意指可耻的叛卖); wolf in sheep's clothing(披着羊皮 的狼); eye for eye, tooth for tooth (以眼还眼, 以牙 还牙) ; wash one' s hand of a thing (洗手不干); new wine in old bottles(旧瓶装新酒); at my wit's end(江郎才 尽, 语出《诗篇》Psalm107:27); Golden calf(金牛犊, 语出《出埃及记》第32章, 后来的拜金主义即源出此语); the light of the world(世界之光, 喻指真理的指引, 基督之道); mother of all living (众生之母, 喻指始祖); salt of the earth (全人类的盐, 在世上发挥作用的人) 等。这些词汇已经成为了英语文化不可缺少的部分。

\section{4. 《圣经》对西方艺术的影响}

众所周知, 艺术和宗教之间紧密相关: 一方面, 艺术 依靠宗教, 宗教占据了社会整体的核心地位, 基本凝聚力; 另一方面, 艺术不仅因为依靠宗教而得到了纵贯历史的辉 煌发展, 而且艺术本身的存在 (形式和内容) 也是统一于 宗教的一一它是宗教活动的一种基本工具和方式。宗教精 神是艺术的内在动机, 艺术与宗教能取得有机的统一。从 这个意义上说, 作为基督教的经典文献——《圣经》, 对 西方艺术的影响也就不言自明了。本文主要从建筑、音乐、 绘画以及影视作品等方面对此进行阐述。

首先, 《圣经》对西方教堂建筑有着不可忽视的影响。 教堂, 即人们为上帝建造的在大地上的居所。因此, 教堂 具有重要的宗教功能, 提供了一种绝对的阻隔和边界, 屏 蔽掉外界的干扰, 使教徒能静下心来与上帝对话。通常教 堂都比较高大、威严、神圣, 其中最著名的教堂就是所罗 门按照神的应许所建造的神殿, 显示了神与人之间的亲密 和谐的关系。因此, “传统的教堂建筑是建立在一种统一 而强有力的意识形态基础上的, 能够吸引和凝聚教徒, 涌 出许多向真、向善、向美的感召与言行, 使其得到一种心 灵的洗礼。” [9]基督教神圣的理念, 尤其是基督教唯灵 主义的理想淋漓尽致地表现在哥特式的建筑之中。哥特式 建筑表现出一种纤细与轻巧, 甚至在某种意义上有点诡异、 神秘的特点。面对着具有唯灵主义精神的哥特式教堂, 人 们会感到一种彻心透骨的悔罪感和光明纯粹的希望。

其次, 《圣经》中音乐无处不在, 其中《诗篇》、《雅 歌》等本来就是歌曲; 《历代志上》23章第5节记载有四 千人用大卫所做的乐器颂赞耶和华; 《历代志下》第5 章 
第11-14节中耶路撒冷落成庆典, 用各种乐器扬声赞美耶 和华。可见, 基督教是最注重音乐的宗教, 但是, 基督教 的上帝不是某一特定种族和国家的崇拜对象, 而是具有超 越种族和国家的普世性; 因此 “音乐家必然超越特定的民 族意识, 将原先各地教会带有地方色彩或民族特点的乐曲 融合起来, 纳入一个更大的音乐文化统一体。”[10]著名 音乐家层出不穷, 谱写出无数的美妙作品来赞美上帝或纪 念《圣经》中的重要事件。比如, 亨德尔的《弥赛亚》全 部歌词依据圣经有关章节写成; 合唱 “哈利路亚” 是西方 古典音乐的保留曲目, 在各种音乐会、宗教庆典、重要场 合上演；“欧洲音乐之父”巴赫的《马太受难曲》、《约 翰受难曲》歌词取自圣经; 海顿的清唱剧《创世记》、《创 世记弥撒曲》、《圣诞节交响曲》、《受难交响曲》、《耶 稣在十字架上的七言》等; 莫扎特的《安魂曲》、《加冕 弥撒曲》、经文歌《欢呼圣体》; 贝多芬的《欢乐颂》充 满了庄严的宗教色彩, 气势辉煌; 李斯特的清唱剧《耶稣 基督》等等。可以说圣经音乐是西方音乐的源头, 孕育了 音乐艺术, 留下了艺术瑰宝; 圣经音乐滋养了人们的心田, 提升了人们的灵魂。

再次, 《圣经》对西方绘画的影响不可小觑。西方绘 画的主题主要是源于希腊罗马神话、民族传说、风俗、各 代帝王将相的肖像、历史事件和人物, 但表现更多、甚至 极为重要, 则是《圣经》的主题, 并被视为唯一 “高尚” 的画种。在西方著名的博物馆、美术馆以及大教堂, 随处 可见直接从《圣经》取材的不朽名画。文艺复兴时期的 达・芬奇圣经故事画品类众多, 包括: 《基督受洗》、《马 里亚领报》、《三王朝拜》、《丁香圣母》《岩间圣母》、

《最后的晚餐》等; 拉斐尔的《坐着的圣母与睡着的圣母》; 《造方舟》、《罗得的逃亡》、《从水中救起摩西》、《渡 过红海》、《摩西击石》等; 米开朗基罗为梵蒂冈西斯廷 小教堂作的穹顶画《创世记》; 之后的海耶兹创作的油画 《路得拾穗》，马赛斯的油画《大卫与拔示巴》等皆取材 于《圣经》。

最后, 现代的影视艺术也体现出《圣经》的巨大影响 力, 一系列的影视作品借助于考古成果、史书记载、传统 以及想象对《圣经》进行诠释, 有些暗含《圣经》因素或 基督教教义, 如《保持缄默》、 《七宗罪》等; 有些是颠 覆性甚至是反《圣经》的, 如《达芬奇密码》等。

\section{5. 《圣经》对西方人日常生活的影响}

西方人的日常社会生活处处浸透了《圣经》。首先, 西方的历法纪年是以耶稣基督的诞辰为元年, 分为“主前” ( $\mathrm{BC}$, 公元前) 和 “主后” ( $\mathrm{AD}$, 公元), 而一周七天的 时间架构也是基于上帝六天创世、第七天休息的经文而创 制。其次, 虔敬教徒的每日祈祷、周日去教堂礼拜、结婚 仪式须在教堂由牧师主持等都反映出《圣经》及基督教的 影响。另外, 西方很多重要的节日都和基督教有关, 例如: 基: 教的圣诞节和复活节已成为西方社会最重要的的节日; 公务人员就职或者在法律上作证, 把手放在《圣经》上宣 誓; 大小城市与乡村, 教堂成为各种社会活动的中心; 人
们常以《圣经》人物命名, 男的如大卫、彼得、约翰、保 罗, 女的如玛利亚、伊丽莎白、萨拉等等。

\section{3. 结语}

西方文化传统的形成是在《圣经》及其基督教文化中 得以整合的, 它包含了古希腊理性主义传统、希伯莱宗教 的精神, 以及罗马人的法治观念。基督教构成了西方社会 近两千年来的文化传统和特色, 它和《圣经》一书对西方 文化的影响是多方面的, 并逐渐渗透到西方哲学、法学、 教育、艺术以及科学等各个领域。如果对《圣经》及其内 涵没有相应的认识和了解, 将会影响对西方文化的深入理 解和恰当运用。因此, 了解《圣经》的内容, 对于更好地 理解西方文化的作用是不言而喻的, 只要我们能通过圣经 文化这个窗口, 对西方的背景文化进行深入学习, 相信会 得到不一样的教益。

\section{致谢}

本文为北京市高等学校 “英才计划” 项目《《圣经〉 的叙事学研究及其对英美文学的影响》(项目编号: YETP0735）的阶段性成果之一。

\section{参考文献}

[1] 刘建军。圣俗相依 [M]. 北京: 中央编译出版社, 2014: 13 .

[2] 赵复三. 基督教与西方文化 $[\mathrm{J}]$. 中国社会科学院研究生院 学报 1987 , 第4期 : 19-20。

[3] 斯蒂芬・米勒, 罗伯特 - 休伯. 《圣经》的历史 [M]. 黄建波, 艾菊红译. 北京: 中央编译出版社, 2012: 307 。

[4] 徐亮, 梁慧。《圣经》与文学 [M]. 北京: 商务印书馆, 2016:222。

[5] 叶舒宪. 《圣经比喻》 [M]. 广西: 广西师范大学出版社, 2003: 79-81。

[6] 刘意青。《圣经》文学阐述教程 $[\mathrm{M}]$. 北京: 北京大学出版 社, 2010 .

[7] 邱永旭. 《圣经》文学研究 $[M]$. 四川: 四川出版集团巴蜀书 社, 2008: 37 .

[8] 菲利普 - W. 康福特. 圣经的来源 $[M]$. 李洪昌译. 上海: 上海 人民出版社, 2011:94-96。

[9] 梁工. 圣经指南 [M]. 哈尔滨: 北方文艺出版社, 2013: 24-28。

[10] 陆扬, 潘朝伟. 《圣经》的文化解读 $[\mathrm{M}]$. 上海: 复旦大学出 版社, 2010: 43。 